\title{
Pragmatics Analysis on Conversational Implicature Used in Mulan (2020) Movie
}

\author{
Yensi Nurisa Simaremare ${ }^{1}$, Wita Cendana Nainggolan ${ }^{2}$, Herman $^{3}$ \\ ${ }^{1,2}$ An Undergraduate student, English Education Department, Universitas HKBP Nommensen, \\ Indonesia \\ ${ }^{3}$ A Lecturer, English Education Department, Universitas HKBP Nommensen, Indonesia
}

\begin{abstract}
:
The research intends to analyze the sorts of dialog and non-observerance observed in the film Mulan, using Grice's theory (2020). This study was carried out using the descriptive qualitative approach. The sort of research is content analysis. As data, the film script for Mulan (2020) was used. In addition, according to Grice's theory, two types of conversational implications exist: a widespread dialog implicitness and a specific dialogic impact and there are 5 sorts of non-compliance maximums: the flushing of a maximum, the infringement of a maximum and the suspension of a maximum. When the researchers collected and analyzed data, they used the data collection, data reduction, data display and conclusion of Miles, Huberman and Saldana idea. In addition, several table and diagram utilized by researchers to accurately describe and measure the data. The results of this study demonstrate that Mulan (2020) movie has 29 utterances that indicate the implications for dialogue. These include 17 widespread dialog involvement (59\%) and 12 specialized involvement. Included in the total (41 percent). In the film from Mulan (2020) it was found that a maximum of 17 data or 58 percent is flouting characters, which is higher than maximum violations, save for maximum manner violations of 9 data or 32 percent. However, the speech of characters in Mulan (2020) film does not contain the other maximum non observance like suspending a maximum and infringing a maximum.
\end{abstract}

Key words: Pragmatics, Implicature, Conversational Implicature, Cooperative principle, Movies

\section{INTRODUCTION}

Language is an important and necessary tool for communication in everyday life. According to Purba and Herman (2020), language is a tool of communication that plays an important role in communication. Furthermore, Vyvyan (2014:1), as cited in Pasaribu, Herman, and Hutahean (2020:12), stated that language is central to our lives, the cultural tool that arguably distinguishes us from other species; central to our lives is communication with other people, socialization with society, and culture. Language, as a communication tool, acts as a unifier in social relationships in society. According to Herman (2018:150), language is a cultural symbol; it denotes that language and culture have a relationship or a bond that is inextricably linked in human life. Humans are more easily able to communicate their desires to other people. In communication, people use language as a device to convey information that people want to convey to others. According to Mohamed (2016:53), we can interact and communicate with people around us through language in order to share everything such as opinion, knowledge, belief, thought, joke, appreciation, and so on. We put everything in our mind into words. That is why language is an important system of communication. Hence, language has a prominent role in communication, especially in conveying information, so there is a specific study to discuss language.

The grammatical position in transmitting information is not the most important element, but it is essential to ensure that listeners correctly convey the notions we wish to convey. Sometimes the 
message is expressed explicitly and implicitly in discussion when we are communication. There are various misunderstandings for the listener. It is because the interpretation of the listener and the ability to understand what the speaker conveys are some variances.

When we try to understand what the speaker says, we frequently fail to recognize that what the speaker said has a deeper meaning than what was conveyed and serves its own function based on the situation we were in. To comprehend this situation, we must first understand the relationship between language and the existing context, as expressed in the form of indirect signs in the language structure. Yule (2010:113) defines pragmatics as the study of the relationship between linguistic forms and the users of those forms. Thus, pragmatics is the study of a language user's ability to correctly combine and adapt sentences. Pragmatic has its own scope as a part of language that also means a study of language that includes aspects outside of language. Hence, Djatmika (2016:12) explains that pragmatic pleased with the speech used by the speaker in interaction, how the same speech can accommodate the intent of a speech can also have the power that makes the interlocutor respond with a certain reaction. Therefore, pragmatic is not only about knowing the actual meaning, We need to know that it is not only about some words named literal meaning; but also can be determined by external features such as when and where the conversation takes place or the situation and culture of the speaker. Pragmatic is a study of how utterance have meaning in situations it means that it has consequently more to do with analysis of what people mean by them (Pasaribu, Herman and Silalahi, 2019; Thao and Herman, 2020; Sinaga, et al, 2020). In short, pragmatic can be defined as the study of context. In order to understand the meaning of conversation, we need to know the function of pragmatic, without it there would be some misunderstanding. Here is the example of pragmatic:

Context: The day when Mulan, her mother and sister met the matchmaker to meet the groom's family. Mulan is already dressed up and wearing thick makeup to meet the qualifications as an excellent bride.

Mulan: Xiu, look at my face. What am I feeling?

Xiu: I have no idea.

Mulan: Exactly. This is my sad face. This is my curious face. And now I'm confused.

(These utterances take from the "Mulan (2020)" Movie)

Based on the conversation above, it is can be seen that Mulan's utterance has another meaning and intention. When she asks about how is her feeling to his sister means that she wants her to take a good look at how thick her makeup is. But Xiu does not know and gets confused, so she directly response with saying that she has no idea. After hearing Xiu's response, Mulan respond it with saying "Exactly" which seems a bit absurd at first, but if we take a closer look, she make a good understanding with Xiu's response. She tried to make Xiu understand about her intention by adding "This is my sad face. This is my curious face. And now I'm confused." By her words, she wants to explain indirectly that her makeup is so thick that she cannot show her feeling with her expression. That is what she intent to explain. Therefore, in order to know the meaning behind the words we need to know pragmatics.

As a result, there are several aspects learned in pragmatics, one of which is Implicature. According to Solihati (2014:23), implicature is meaning that is not explicitly conveyed in what is said but can be inferred. In other words, Implicature is the meaning that the speaker wants to convey but is not part of what is said. What is said has another meaning than what is revealed. The meaning can be known the context of the components involved in conversation, including who the speaker is, who the hearer is and what they mean to their own messages. 
Conversational implicature, according to Ardine and Ariyanti (2016:17-26), can also be used to determine the implicit meaning behind what people say or write as what people implicate to. That is why people are expected to cooperate when speaking. When they are uncooperative during a conversation, it is because they want to implicate something in order to avoid speaking directly to the point. At addition, Lailah (2016:8) claimed that involvement is a further level in which the meaning of the speaker may alter, depending on the discussion setting. What is meant by talk involvement is not so much expressed by what is said as by the fact that it is uttered. Moreover, those participating should take part and work together in order to arrange the content of the conversation well. This approach is also known as the principle of cooperation.

According to Septimayola (2020:12), the principle of cooperation is the primary premise we make while speaking to each other: we try to cooperate to build meaningful discussions. While the speaker is speaking, the listener will automatically make an assumption about the meaning of the sentence whether it is an implicit or explicit meaning. Therefore, Grice as cited in Sitorus et al (2019:64) suggests a cooperative principle which has an important role in implicature. In order to serve an efficient means of communication, he is formulated a general principle of language in the basic rules or maxims. They are: (a) maxim of quantity (be brief); (b) maxim of quality (be true); (c) maxim of relation (relevant); (d) maxim of manner (be clear).

In addition, in the entertainment sector such as film industry the phenomena of conversational implications arises. Muvida (2015:1) states that a film is a linguistic tool which employs moving images to convey ideas, tales, perceptions, sentiments, beauty and atmosphere. The audience halt for a time in order to examine the significance or the purpose of what is being uttered by most of the characters in the film. Many charters in the film have deliberately breached the cooperation principle (Vikry, 2014:2). This film has several different characteristics, who make many implicit statements to be examined utilizing conversational implications.

Here's a scene from the movie with an example of conversational implicature:

Context: In the House of Hua family, Hua Zhou and His Wife were talking about the edict of His Imperial majesty, The Emperor, to contribute one man of each family to fight.

Hua Zhou's wife $\quad$ : You're a war hero. You've already made many great sacrifices.

Hua Zhou

: Are you suggesting our family not comply with the imperial edict?

(These utterances take from the "Mulan (2020)" Movie)

From the foregoing example, we can see that he is flouted because he did not answer straight away and is not relevant to the assertion of his wife. Hua Zhou's utterance signifies more than he says. Grice's theory of conversational implications is used to evaluate this speech; the implication is arranged as a specific discussion implicitity. The additional significance is computed with a particular understanding of every specific setting and is not stated literally to receive the message of the speech. Conversational implications therefore signify implicitly in the sentences which are not described in the speech about the context in which they were said.

Some scientists also concentrated on Implicacy. The first is a paper by Muhamad Vikry entitled "an analysis of the impact of conversation in Iron Man 3." (2014). The objective of this study is to classify the sorts of talk involvement that arose from the failure of the characters to see maxims in the movie Iron Man 3 and to then explain their implications. The scholars have employed the theory of Grice to assess the dialog implications of the characters of the film. Researchers carried out the research utilizing a qualitative descriptive method to describe and determine the dialog implication, without the use of statistical methods. Data were collected for this study by looking at the movie and noting the dialogs predicted to be involved in data cards. The selected data is analyzed one by one 
using the corresponding research hypothesis.

The study found that the characters had increasing conversational implications due to nonobservance maxims: the maximum amount of flutter (2), quality maximum fluttering (2), the maximum ratio of fluttering (2) and the maximum amount of flutter (5) which the study requested (5). (1). The researchers have found two kinds of conversational implications: widespread dialog (2) and a specific dialog implications (3). (13).

The second study was carried out by Maulina Nur Putri from UIN Sunan Ampel Surabaya (2020). This article is titled "The Analysis of the Implications of Conversation in the Midnight Sun Film." This study aims to examine the sorts of conversational implication and the maxims violated or flouted in Katie and Charlie in the Midnight Sun film. Based on Grice's theory (1975), the researchers studied the various types of dialog and concealed meanings, and violated or flooded maxims. Researchers have employed descriptive qualitative approaches. By downloading the Midnight Sun script from the internet, researchers obtained information. The scientists describe the utterances contained in the conversational involvement category and code the data after their data gathering. The investigators then assess the meaning behind them and classify the statements as being in violation or in violation of the maxim. Researchers discovered that the two major characters more commonly employed a specific conversational implication than a general conversational one, based on the findings of this study. Besides that, both Katie and Charlie more frequently infringe maxims than they blur.

The third study was carried out by Rahmat Fuad Siregar at Sumatera Utara University (2018). The work is titled "An Analysis for Vandetta Movie on Conversational Implications." Using Grice's theory, this thesis looks at the widespread and specific discussion implications found in $\mathrm{V}$ for Vendetta. The problem with this theory is the interpretation of implicit significance and the failure to meet maximum requirements. The aim is to understand the inferred significance and to find out how speakers cannot achieve maximum conversational implications in every picked word. As the data is expressed through dialogues, the approach of study is qualitative in terms of description. The study shows 52 implications for Vendetta for the conversation: 21 widespread implications for the talk and 31 specific implications. 34 failures, comprising 21 infringements and thirteen floods, are implemented. 33 of the faults are in PCI, while one is in GCI. The movie violates and flatters all maxims (maximum quality, maximum quantities, maximum significance and maximum of manners); it does not opt out and face conflict. Most of the consequences of observing the cooperative principle are caused by broad conversational implications. However, the main trigger for this impact is the specific conversational ramifications of breaching and flouting maxims. The results of the analyzes provide a more detailed examination as to how, in some situations, utterances may only be comprehended in dialogues by taking account of contexts that incorporate them into complete meanings, as seen in Film V for Vendetta. Speakers often employ difficult means of communication, such as erroneous communication without lying or lying intentionally, to express their opinions and goals. The co-operative principle and maxims of Grice are two important things to be remembered when anybody in their pronunciation implies something. Conversational implications are an intriguing perspective on the meaning of a speaker in real communication, and a discussion of meaning is highly suggested for future studies.

Based on previous studies above, the researchers found that both Muhamad (2014) and Rahmad (2020) analyze the same genre of Movie that is Action and focused on the Implicature that is found in the conversation. On the other hand, Maulina (2020) analyze a Romance genre but these researches focused on non-observance of the maxim and types of conversational implicature in the movies. The difficulty with these theses is also the perception of implicit meaning and the failure to meet maximums. The goal is to understand the inferred meaning and to find out how the speakers in 
every selected speech that has conversational implications are not able to achieve maxims.

This research, therefore focused on the conversational implications of the film of Mulán (2020), based on Grice Theory, based on the prior studies described above. The investigations selected Mulan (2020) Movie as it was fascinating for the scientists to learn how the implied meaning of the statements spoken by characters in Mulan movie is to be understood as a way of understanding its meaning based on the context, the types of conversation and the type of maxims. Finally, the researchers hope through this research, it can show the reason why we need to understand about the implied meaning in conversation and make them, as the hearers, wiser in order to make good response to the speaker.

\section{RESEARCH METHODOLOGY}

\section{Design of the Research}

This is a qualitative research. In Fauziyah (2016:8) qualitative research is described as narrative or textual descriptions of investigated phenomena, in Venderstoep and Johnston (2009:7). "Qualitative research begins with a question: its ultimate purpose is learning," according to Rossman and Raliss (2012:3). In order to inform queries, the researchers collected data or basic information units or building blocks. The data are pictures, sounds, words and numbers." Creswell (2016:43) defines qualitative as an understanding inquiry process based on diverse methodological research traditions that examine a social or human topic. The research builds a sophisticated, integral image, analyzes words, reports detailed information views and takes place in a natural environment (Herman et al, 2019). Qualitative research is a study type that investigates and understands the meaning of a number of people or groups touched by a social problem. Qualitative research can generally be used to examine the lives of people, their history, conduct, concepts or phenomena, social problems, etc. Briefly, qualitative research is based on the scenarios, topics, conditions and context that films/films convey.

As a result of the data obtained through observation, the researchers used descriptive qualitative methods. It began with gathering, analyzing, and drawing conclusions from data. Suryana (2010:14), as cited in Satriadi (2014:31), affirms that descriptive research is focused on making a systematic and accurate description of facts about a specific object. The information was gathered from the characters' utterances in the Mulan film.

\section{Data and Data Source of the Research}

Data is factual information. Data is one of the most important aspects of determining research results. A qualified study, according to Arikunto (2010:21-22), is one that contains complete data, both primary and secondary data. Primary data is data in the form of verbal or spoken words, gestures, or behavior by subjects who can be trusted, in this case research subjects (informants) with respect to the variable owned. Secondary data is information obtained from documents graphics (tables, records, meeting notes, SMS, etc.), photographs, films, video recordings, objects, and other sources that can be used to supplement primary data.

In this research, the data from Mulan (2020) Movie were taken from the above description. This link shows the movie: https:/www.hotstar.com/id/films/mulan/1260048586/watch. Mulan is a Walt Disney Pictures 2020 American fantasy action drama. This live-action rendition of Disney's 1998 same-name animated picture, "The Ballad of Mulan," is based on the Chinese traditional story. The plot is in the Imperial China, where the eldest daughter of a warrior Hua Mulan masks as a man in a mass conscription against the Rouran army, who is taking her father's position. The research chose Mulan (2020) Movie because the researchers found that it is really fascinating to know the role of implicature in understanding the implied meaning from the utterances that the characters in Mulan 
movie spoke, how the other characters gave the response as the form of understanding the meaning based on the context they were in, the types of conversational and the kinds of maxims of cooperative principle that are non-observance in utterance between the characters in Mulan (2020) Movie. Finally, the researchers hoped through this research, it can show the reason why we need to understand about the implied meaning in conversation and make them, as the hearers, wiser in order to make good response to the speaker.

\section{Instruments of the Research}

This study's instrument was the researchers themselves. Here, as the instrument for data collection, researchers were able to better comprehend the data in order to provide more clear and accurate information. According to Ary et al. (2010: 421), the primary instrument used for data collection in qualitative research is the researchers, who often collect data through direct observation or interview; thus, the researcher is the instrument of this research. Furthermore, data collection instruments such as stationary, laptops, and so on are used.

\section{Technique of Data Collection}

According to Arikunto (2010:25), the exact method for qualitative research is a combination of various data sources and data collection methods (e.g., from books or videos) (Herman, 2015; Thao and Herman, 2021). He also mentioned the fifth type of research instrument, which were interviews, questionnaires, observation, documentation, and testing (2006:160). As a result, the researchers used Observation and Documentation to collect data for this study. Observation in qualitative research is one of the oldest and most essential ways to research. McKechnie (2008:573) defines this technique as "the systematic and purposeful collection of facts by means of one's senses, especially gazing and listening." Documentations are utilized in qualitative research by analyzing the content. According to Arikunto (2010:202-203), the means of documenting are for notes, transcripts, book, newspapers, magazines, inscriptions, meeting notes and so on, which look for information about items or variables. Documentation is a benefit as a data collection method, because the data remain unchanged even while an error is made during data recovery.

The data collection process began with observing the movie's content, such as the characters, utterances, behaviors, conditions, and others. The researchers then made some notes and codes using the Documentation method to collect data from the movie's transcript of the conversation. Here are some methods for gathering data in order to complete the research:

1. The researchers downloaded movie and script Mulan (2020) Movie in Google. The researchers chose Hotstar link to watch the movie as follow: https://www.hotstar.com/id/movies/mulan/1260048586/watch provides free movies with good quality picture, sound, and script which can support the accurateness of data.

2. The researchers watched Mulan (2020) movie to check the accurateness of English transcription with the motion picture.

3. Continue to selecting data from the result of watching Mulan (2020) movie.

4. Classifying data in forms of conversational implicature.

5. Arranging the obtainable data systematically.

\section{Technique of Data Analysis}

As for analyzing data, in this research used contents analysis. The contents received after making some notes and observing the data. The data was analyzed by using the theory of Miles, Huberman \& Saldana (2014:69) concept. After collecting the data from the Movie, the researchers precede to the 
next step as follows based on Miles, Huberman \& Saldana (2014) concept:

\section{Data Reduction}

The first step is data reduction, which is the process of selecting, focusing, simplifying, abstracting, searching for themes and patterns, and discarding irrelevant data. From the data that has been selected through some observation and documentation notes/ codes from the movie, the researchers continued with selecting and focusing on the data to make it into a narrative text.

a. Researchers used a table to classify data

b. After making these codes, the example of bolding and giving code in movie transcript present as:

00:03:35 Don't panic. There's a spider crawling in your hair. (PCI-VR)

01:25:36 Impossible. A woman leading a man's army. (GCI-FR)

\section{Data Display}

The data display phase comes after the data has been classified and collected. It was done in the form of a brief description using narrative text; however, it can also be done using graphics, a matrix, and a chart.

\section{Conclusion}

The final step is to come to a conclusion. In this study, data such as the utterances spoken in the movie were written in the data display. The data displayed is further analyzed to draw conclusions.

\section{RESEARCH FINDINGS AND DISCUSSION}

\section{Research Findings}

The researchers uncovered 29 data on the implications of conversations that include varieties of dialog implications and link to the kind of maxims of the principle of co-operative observation after researching the implications of conversations revealed in the Mulan movie (2020). There are 17 generic data on the implication and 12 particular data on the implication of dialogue. In addition, the maximums identified in Mulan's film (2020) for non-observance are 9 infringement data, 17 flout data for a maximum and 3 data for maximum single option while maximum violation and suspension are absent. The characters of Mulan (2020) film show all these sorts in the utterances.

Table 1. Total Number of Conversational Implicature found in Mulan Movie

\begin{tabular}{|c|c|c|c|}
\hline No. & Types of Conversational Implicature & Frequency & Percentage \\
\hline 1. & Generalized Conversational Implicature & 17 & $59 \%$ \\
\hline 2. & Particularized Conversational Implicature & 12 & $41 \%$ \\
\hline \multicolumn{2}{|c|}{ Total } & 29 & $100 \%$ \\
\hline
\end{tabular}

Table 1 shows 29 kinds of dialog involvement identified in the film Mulan (2020). The above table illustrates that the characteristics of Mulan's (2020) film "Generalized Conversational Implicatura" are most important among particular conversational implications. It is the largest form of conversational involvement, consisting of 17 data out of 29 data, or $59 \%$. Then there are 12 data out of the 35 data or $41 \%$ data. conversational involvement.

Hence, the researchers also found that there were 29 non-observance maxim found in Mulan (2020) movie. The table above shows that flouting a maxim, 17 data or $58 \%$, is higher than violating maxim, except for violating maxim of manner, 9 data or $32 \%$, and opting out of a maxim takes 3 data or $10 \%$. On the other hand, the other non-observance maxim such as suspending a maxim and infringing a maxim is not found in the utterance of the characters in Mulan (2020) movie. 


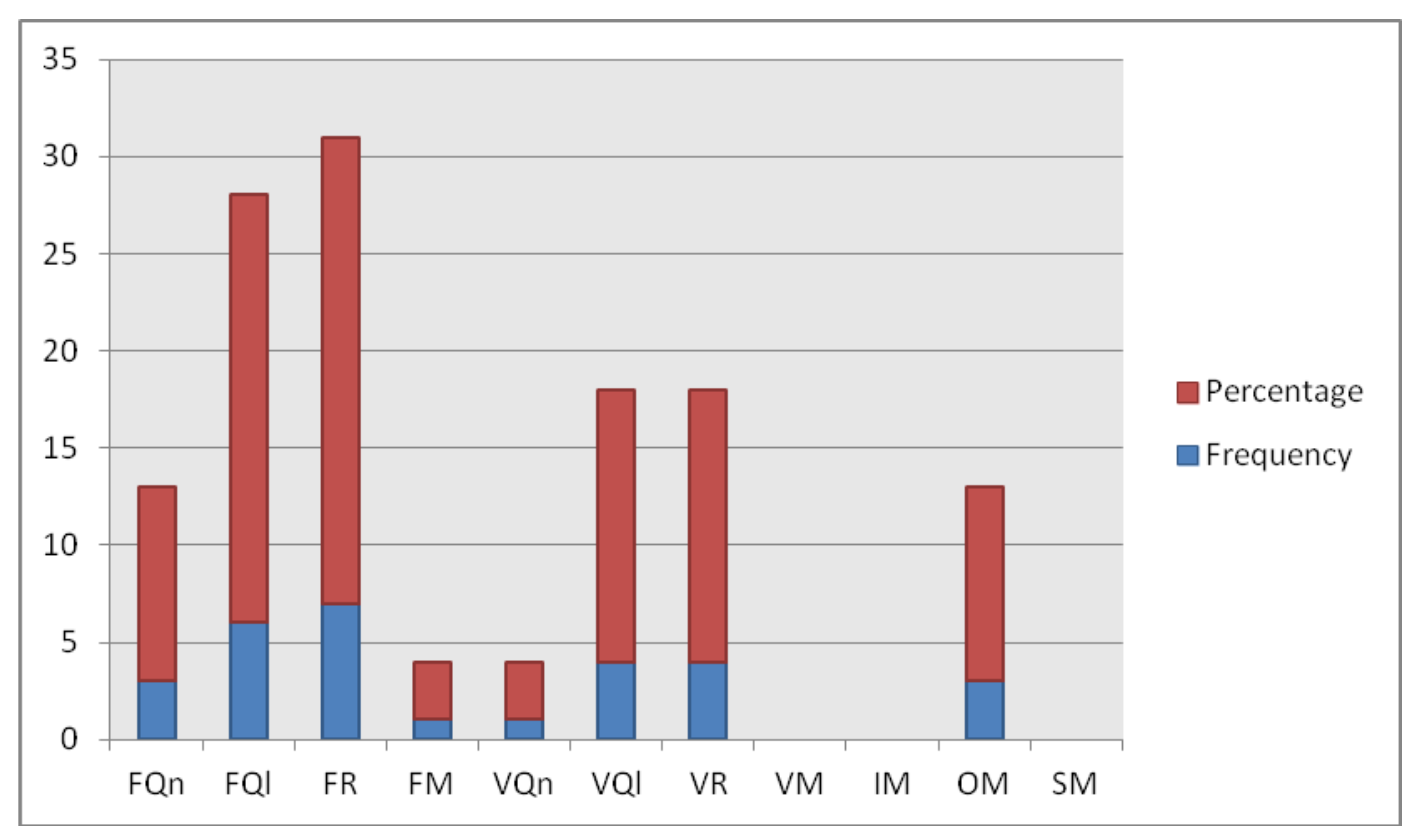

Chart 1 Non- Observance Maxims found in Mulan Movie

\section{Discussion}

This study was designed to investigate the many kinds of dialog involvement and non-observance norms found in the Mulan film (2020). The two sorts of conversational implication are widespread discussion and a particular dialog implication. There is also non-observance, which is grouped into five different types: a maximum violation, a maximum flush, a maximum option, a maximal infringement and a maximum suspension. The finding of the kinds of conversational implication showed that 29 statements were made in the characters at Mulan (2020). There are 17 generic data on the implication and 12 particular data on the implication of dialogue. Moreover, the maxima of nonobservation discovered in the film Mulan (2020) is 9 infringers of a maximum, 17 infringers of a maximum and 3 infringers of only one maximum. On the basis of the aforementioned results, we can see that the widespread implications of conversation are utilized more than the specific implications of conversation in the Mulan (2020) film, since most utterances are used without any understanding and fully knowing the context in respect of their circumstances. On the other hand, it is frequent for a maxim to defy, particularly by neglecting a maximum pertinence, than other typical non-observance maxims, because in Mulan (2020) certain characters alter the topic purposefully and shamelessly and avoid speaking of a particular topic. There is also no infringement and no suspension of the maxim because the words are shouted out plainly and also because the characters in Mulan's movie comprehend the context fully and are openly spoken. Through this study in the research, the researchers have observed that some conditions make people choose to indicate their significance implicitly in their statements. This event is caused by purposes such as: encouraging somebody, misleading people without lying, softly giving advise, etc. These results show certain similarities and differences in comparison with other studies. First, Putri's (2020) research showed the sorts, significance of each conversational implication as well as the maxims of communication being flouted and violated. In her research, the conclusion has revealed that the specific implication is higher because the major characters hide a secret, which means that in order to comprehend the meaning of the speaker, the addresser requires more explanation because the context is specific. In addition, infringeing maximum values are more prevalent between breaking and flouting, and particularly in breaking maximum quality, because it is necessary for the speaker to state something based on the truth. Secondly, the Siregar (2018) research reveals the implications and how in each 
conversational implication the speaker is unable to achieve a maximum. The results found that the film is dominated by a certain talkative implication, so the adressor should be clever to understand the meaning of the words and to watch the situation in which they are. Moreover, because a certain conversational involvement dominates more, the maximum non-observance occurs in the discussion generally. The connection between contexts and maxims is proven to be robust in the conversational setting. Thirdly, the Vikry research (2014) reveals the maxims of non-observance, the nature of the dialog and the meaning of each conversational implication. He noticed that the specific implication of conversation is more prominent and most of the implication of communication is increased, since the characters are flawing. On the basis of these researchers, it can be seen that most of the prominent varieties of discussion are particular conversational, whereas researchers concluded that widespread dialog is more dominant, which is different from the previous research. It's due to the fact that in their utterances the characters in Mulan (2020) are implicit but ensure the addressee certainly has their meanings because a certain knowledge is not needed but instead their context. Furthermore, the flout maximum is more prevalent than other forms of non-observance maximum, especially because they are plain in their conversations and also shift the topic flagrantly in order to alter the subject. In short, there is indeed a connection between the implication of dialogue and the principle of cooperation: we can see from the film and from the study that individuals somehow wish to tell what they intend obliquely and impliedly. In order to respond to their significance, as the recipient, we need to know how to talk together, which is why we must follow the concept of cooperation so that we can convey our meanings correctly, which shows that we comprehend the results of the conversation. In addition, it is crucial to comprehend the meaning behind the speech in the discussion and to pay attention also to the context in which the conversation has taken place to get a sense of the meaning and the aim of the speaker so that the conversation may flow smoothly.

\section{CONCLUSIONS}

The goal of this study is to detect the sorts of conversational implications and the maximum of nonobservance in the film Mulan (2020). The information came from the statements of the characters in the film Mulan (2020). The aim of this study is to determine the many sorts of maxims produced by the character for conversational implication and non-compliance. From data the researchers found that the widespread dialog implications are more widespread than the specific conversational implications, with 17 of 29 data. The implication is because the characters violate a rule, especially an important rule. This is because the characters in the Mulan (2020) film attempt intentionally to alter and to evade the subject by expressing themselves, however they do not have to confirm its significance because the adressor knows the meaning behind their statements on the basis of the context. In the movie Mulan (2020) there is a widespread conversational implication, because most people use their words with intended to be direct, even if they aren't specific, depending on the setting and situation in which they live. As a result, no particular information or explanation is necessary for the speaker to appreciate the implications in his speeches. The listener must have a specific knowledge or explanation for the specific conversational implication and it is more complicated to understand a particular specific discussion implications, than a general conversation implicitness, because most speakers imply their expression in widespread conversation with the intention that $\mathrm{m}$ Finally, the researchers found 29 utterances containing implications in the Mulan film (2020), including 17 utterances categorised as generic conversational implications and 12 utterances classified as specific conversational implications. Furthermore, it has been found that the characters in the Mulan (2020) film blurred, violated and decided not to speak as much as possible. Characters are 7 times more relevant, 6 times more relevant than maximum, 3 times higher than maximum and 1 time higher than maximal. Other failures such as a 4-fold breaking of maximal quality, maximum amount 1-fold, maximum pertinence 4-fold, and maximum way none were followed. Mulan also opts for a maximum of three times, one of the characters. The characters, by 
saying things which have an indirect meaning in their words, try to avoid or change a specific topic, but make sure that the adresser will catch up with their intention because there is no need for specific knowledge, but simply because they must follow the context in which they have been.

\section{REFERENCES}

1. Arikunto, S. (2010). Prosedur Penelitian Suatu Pendekatan Praktik. Jakarta: Rineka Cipta.

2. Ary, Donald.et. al. (2010). Introduction to Research in Education. United States: Wards worth.

3. Creswell, John W. (2016). Research Design: Pendekatan Metode Kualitatif, Kuantitatif dan Campuran. Edisi keempat (Cetakan Kesatu). Yogyakarta: Pustaka Belajar.

4. Djamatika. (2016). Mengenal Pragmatik Yuk. Yogyakarta: Pustaka Pelajar.

5. Fauziyah, Nadya Alfi. (2016). Conversational Implicature on the Talk Show. Thesis. Malang: Maulana Malik Ibrahim State Islamic University.

6. Herman. (2015). Illocutionary Acts Analysis of Chinese in Pematangsiantar. International Journal of Humanities and Social Science Invention, Volume 4 Issue 12, PP.41-48. Retrieved from http://www.ijhssi.org/papers/v4(12)/Version-2/E0401202041048.pdf

7. Herman, Murni, S. M., Sibarani, B. and Saragih, A. (2019). Structures of Representational Metafunctions of the "Cheng Beng" Ceremony in Pematangsiantar: A Multimodal Analysis. International Journal of Innovation, Creativity and Change., Volume 8, Issue 4, 2019. Retrieved from https://www.ijicc.net/images/vol8iss4/8403_Herman_2019_E_R.pdf

8. McKechnie, L. E. F. (2008). Observational research. In Given, L. M. (Ed.), The Sage encyclopedia of qualitative research methods. Page 573-577. Thousand Oaks, CA: Sage.

9. Miles, M.B, Huberman, A.M, dan Saldana, J. (2014). Qualitative Data Analysis, a Methods Sourcebook, Edition 3. USA: Sage Publications. Terjemahan Tjetjep Rohindi Rohidi, UI-Press.

10. Mohamed, K. O. S. (2016). "Translation and Community Integration". Global Journal of Arts, Humanities and Social Sciences. Vol. 4(1), Page 53-56.

11. Muvida, Asrorul Nur. (2015). "Conversational Implicature that is used by Three Main Characters in Hotel Transylvania Movie". Yogyakarta: Universitas Islam Sunan Kalijaga.

12. Purba, R. and Herman. (2020). Multimodal Analysis on Ertiga Car Advertisement. Wiralodra English Journal (WEJ), Vol 4 No 1 Maret 2020, PP. 21-32. Retrieved from http://wej.unwir.ac.id/index.php/wej/article/view/77

13. Pasaribu, B., Herman, and Hutahaean, D. T. (2020). Students' Difficulties In Translating Narrative Text From English Into Indonesia At Grade VIII Of SMP Negeri 9 Pematangsiantar. Acitya: Journal of Teaching \& Education, Vol. 2 No. 1 2020, PP. 12-18. Retrieved from http://journals.umkt.ac.id/index.php/acitya/article/view/1311

14. Pasaribu, S., Herman, Silalahi, D. E. (2019). The Speech Acts Between Teacher and Students in Teaching and Learning Process. Multidisciplinary European Academic Journal, Issue Vol 1 No 1. Retrieved from https://www.syniutajournals.com/index.php/MEAJ/article/view/94

15. Putri, Mauliana Nur. (2020). The Analysis of Conversational implicature in "Midnight Sun" Movie. Thesis. Surabaya: UIN Sunan Ample.

16. Satriadi, N.P, (2014). An Analysis Translation Procedure on Sony Ericsson Live with Walkman Startup Guide. Thesis. Bandung: Indonesia University of Education.

17. Septimayola, R. Y, (2020). Conversational Implicature in Beauty and The Beast Movie. Thesis. 
Jambi: State Islamic University of Sultan Thaha Saifuddin.

18. Sinaga, D., Herman., and Marpaung, T. I. (2020). Deixis in the Song Lyrics of Lewis Capaldi's "Breach" Album. JOLLT Journal of Languages and Language Teaching, P-ISSN: 2338-0810, Vol 8, No 4 (2020), E-ISSN: 2621-1378, PP. 450-457. Retrieved from http://ojs.ikipmataram.ac.id/index.php/jollt/article/view/2843

19. Siregar, Rahmat Fuad. (2018). An Analysis of Conversational Implicature in "V for Vendetta" Movie. Thesis. Medan: University of North Sumatera.

20. Sitorus, Lungguk, Fauziah Nur, \& Lilis. (2019). "Implicature in The Devil Wears Prada Film”. Journal of Language, Literature, and Teaching. Vol. 1(2), Page 63-72

21. Solihati, Nurngaini. (2014). Conversational Implicature in a Drama Entitled Snow White and the Seven Dwarfs and Its Application in Language Teaching. Thesis. Purwejo: Muhammadiyah University of Purwejo.

22. Thao, N. V. and Herman. (2020). An Analysis of Deixis to Song Lyrics "My Heart Will Go on" by Celine Dion. Communication and Linguistics Studies. Vol. 6, No. 2, 2020, pp. 23-26. Retrieved from http://www.sciencepublishinggroup.com/journal/paperinfo?journalid=357\&doi=10.11648/j.cls.2 0200602.12

23. Thao, N. V. \& Herman. (2021). An Analysis of Idiomatic Expressions Found in Ed Sheeran's Selected Lyrics Songs. CENTRAL ASIAN JOURNAL OF LITERATURE, PHILOSOPHY AND CULTURE, 2(1), 12-18. $\quad$ Retrieved from http://cajlpc.centralasianstudies.org/index.php/CAJLPC/article/view/54

24. Yule, G. (2010). The Study of Language: 4th Ed. New York: Cambridge: University Press. 